\title{
BARRIERS TO CARE AND CURRENT MEDICAL AND SOCIAL NEEDS OF HIV-POSITIVE PATIENTS IN ALBANIA
}

\author{
Shane D. Morrison ${ }^{1}$, Vilson H. Banushi' ${ }^{2}$ Clea Sarnquist ${ }^{1}$, Valbona H. Gashi ${ }^{2}$, Lars Osterberg ${ }^{3}$, \\ Yvonne Maldonado', Arjan Harxhi \\ 'Department of Pediatrics, Stanford University School of Medicine, Stanford, California, USA \\ ${ }^{2}$ Department of Infectious Diseases, University of Tirana School of Medicine, Tirana, Albania \\ ${ }^{3}$ Department of Medicine, Stanford University School of Medicine, Stanford, California, USA
}

\section{SUMMARY}

Objective: As HIVIAIDS prevalence rises in Eastern Europe, assessment of local epidemics in the bordering Central European region, especially South Eastern Europe, is vital in order to meet treatment and prevention needs. Understanding current medical and social needs and barriers to care experienced by HIV-positive patients in these regions may provide insight into how to best respond to the local epidemics, increase patients' access to treatment, and reduce loss to follow-up.

Design: This study assesses the patient characteristics, barriers to care, and current medical and social needs of HIV-positive patients in Albania. Semi-structured interviews were used in this cross-sectional study.

Methods: We interviewed 79 of 85 patients ( $93 \%$ response rate) followed at the University Hospital Center of Tirana (UHCT) HIVIAIDS Ambulatory Clinic, which represented the majority of patients under HIV care in Albania during 2009.

Results: The local HIV epidemic seems to be comprised mainly of heterosexual men who have spent an average of 3.6 years abroad. The vast majority of patients under care at UHCT HIVIAIDS Ambulatory Clinic had experienced barriers to care associated with social stigma (97.4\%), lack of knowledge of HIV medical care (76.6\%), and medical provider's lack of knowledge of HIV (70.9\%). Social needs of the patients were also overwhelmingly unmet (90.0-95.7\%).

Conclusions: In addressing HIVIAIDS in Albania, it will be crucial to educate the healthcare sector in ways to identify and address barriers to care and current medical and social needs of HIV-positive patients.

Key words: barriers to care, HIV, health service needs, Central Europe, Albania

Address for correspondence: S. D. Morrison, Stanford University School of Medicine, Medical School Office Building, 251 Campus Drive, Stanford, CA, 94305, TN 520 850-0495. E-mail: shanem@stanford.edu

\section{INTRODUCTION}

Eastern Europe currently has one of the fastest growing HIV prevalences in the world (1-6). As an increasing number of individuals is diagnosed with HIV throughout the region and heterosexual contact is becoming a major risk factor, many countries in Central and Eastern Europe have started to increase awareness especially through HIV surveillance, prevention, and treatment programs (7-10). Given these trends in Eastern Europe, an indepth look at the local HIV epidemics in neighboring Central European countries, especially some of the South Eastern European post-communist countries, is warranted. This is particularly true for the Balkans where little information about HIV infection is available. In the Balkans, reported country HIV prevalence data is variable and antiretroviral therapy (ART) resistant strains of HIV have been found in antiretroviral-naïve individuals, highlighting the necessity for additional information on the HIV epidemic within these countries (11-13). Recent political conflicts and the unstable sociopolitical climate in Albania have produced a favourable environment for the spread of HIV; however, the Ministry of
Health $(\mathrm{MoH})$ reports that the prevalence of HIV/AIDS is $<0.01$ $\%$ (359 people in the country of 3.1 million have been diagnosed) $(14,15)$. The MoH acknowledges that the prevalence may be higher even though the reported number of people with HIV/ AIDS remains relatively low $(16,17)$. Surveillance programs for assessing the situation in Albania are under-resourced, and only a few major cities have been partially surveyed (18).

The absence of a fully operational surveillance system is worrisome given the characteristics of the Albanian population. Albania is the youngest country in Europe with an average age of 29 and $40 \%$ of the population is under 18 years of age, while more than $30 \%$ of the population lives below the poverty line. Since Albania emerged from isolation in 1992, risky behavioural practices have been increasing particularly in the younger and marginalized population groups (including the highly discriminated Roma population, intravenous drug users (IDUs), and men who have sex with men). Based on initial surveys, condom use varies from $5-36 \%$ and needle sharing amongst IDUs was estimated at $66 \%$ $(14,16,18-20)$. Increased prevalence of human trafficking and sex work amongst the migratory population also offers causes for 
concern (19). As of 2005, 27.5\% of the population had emigrated with an unknown number returning to Albania (21).

Though the number of HIV/AIDS cases in Albania is reportedly low, the prevalence of HIV/AIDS based on these same statistics shows a ten-fold increase from 1996 to 2002 with $87 \%$ of the cases derived from heterosexual contact $(14,16,17)$. Genetic analysis of plasma samples from ART-naïve patients in Albania paints a different picture on the prevalence rates, however. The molecular epidemiological studies with these samples suggest that high estimates of the prevalence of different HIV strains in Albania are 10,000 for HIV-1B and 30,000 for HIV-1A indicating a possible prevalence of $1.3 \%$ (150-fold the current estimate) $(22,23)$.

While there have been many advances in the treatment of HIV/ AIDS in developing countries, there are still many limitations for accessing HIV/AIDS medical care $(24,25)$. These barriers can be rooted within the population or healthcare sector and have dramatic effects on treatment and prevention of HIV/AIDS (26). Fear of social stigma, limited knowledge of HIV/AIDS by both healthcare providers and the general population, and inability to locate proper care are common barriers in resource-limited countries (27-32). Patients that fail to navigate these barriers may not get the care they need. Addressing access to care has entered the fore on policy issues for HIV/AIDS in many Eastern and Central European countries, especially for marginalized populations ( 9 , $30,33,34)$.

Should the epidemic in Eastern Europe spread into neighboring regions, it would be vital for countries, like Albania, to understand the characteristics of their local epidemic in order to effectively treat those infected and prevent further spread. Therefore, in this study we set out to determine the characteristics of the HIVpositive patient population at the University Hospital Center of Tirana (UHCT) HIV/AIDS Ambulatory Clinic, and understand their barriers to care. Current medical and social needs of the patients were also explored in an effort to determine areas that the healthcare sector in Albania may be able to address in the future.

\section{METHODS}

\section{Study Setting}

The study was conducted at the UHCT HIV/AIDS Ambulatory Clinic in Tirana, Albania. The HIV/AIDS clinic is the only clinic in Albania that offers ART, which was initiated in Albania in 2004 (16). Patients are referred to the clinic from other divisions within the UHCT as well as other local hospitals and clinics throughout Albania. Initial HIV testing occurs on-site or at the Public Health Institute of Albania, and a counselling session is provided if a patient receives a positive HIV test result. Patients are monitored and treated for possible infections until their CD4 count drops below 350 cells $/ \mathrm{mm}^{3}$, at which point ART is initiated free of charge. At the time of this study, patients were not initiated on ART until their CD4 counts were less than 200 cells $/ \mathrm{mm}^{3}$. Before therapy is started, the patient is given another counselling session with the on-site psychologist at the HIV/AIDS Ambulatory Clinic. ART is then dispensed on a monthly basis, or bimonthly basis if the patients live outside Tirana, and monitored via a pharmacy record on ART prescribed.

\section{Patient Population}

There have been approximately 300 non-pediatric patients that have initiated HIV/AIDS medical treatment at the UHCT HIV/AIDS Ambulatory Clinic since 2004. While this study was being conducted (June-August 2009), there were 85 patients under HIV medical care. Of those patients, 79 (93\%) agreed to participate in the study; $68(86 \%)$ of those participants were on ART. Patients under 18 years of age $(n=0)$ or those unwilling to participate in the study $(n=6)$ were excluded. Before participation, patients underwent an informed consent performed by the on-site psychologist in Albanian. For participation in the study, patients were given 400 Leke ( $\$ 5$ USD).

\section{Survey}

The instrument was developed in conjunction with Stanford University School of Medicine, the UHCT HIV/AIDS Ambulatory Clinic, and the Ministry of Health in Albania. This survey contained separate parts for demographic data, barriers to care, and current medical and social needs of the patient. Each question was adapted from surveys used in previous major research projects in the U.S. and developing countries (Sarnquist $\mathrm{C}$ and Maldonado $\mathrm{Y}$, personal communication) $(18,35,36)$.

The survey instrument was translated into Albanian by a bilingual Albanian with expertise in the medical field. Bilingual physicians at the UHCT HIV/AIDS Ambulatory Clinic backtranslated the instrument into English to assure accuracy. Different physicians at the UHCT HIV/AIDS Ambulatory Clinic then checked the survey for errors and cultural appropriateness. Following their final approval, the survey was given to patients in the form of structured interviews due to the low literacy rates. Either the on-site psychologist (VHB) or the on-site physician (VHG) conducted the structured interviews. The interviewers were trained in the structured interview process. The questions were both closed- and open-ended. The Stanford University Institutional Review Board and the Albanian Ethical Committee approved the study.

\section{Data Analysis}

All data compiled from the study was coded and stored electronically. Ten percent of the data was reentered to check for errors and there were none identified. Characteristics of the patient population are presented as absolute number and percentage for categorical variables, and mean and standard deviation for continuous variables. Barriers to care and current medical and social needs are presented in both absolute respondent numbers and frequencies. Barriers to care were placed in a rank-ordered fashion. Most difficult barriers to overcome were grouped into general categories based on patient responses. They were placed in a rank ordered fashion and smaller subsets, like stigma and psychological problems, were generated to further parse the data. Current medical and social needs of the patients were not placed in a rank ordered fashion due to inclusion of data on whether or not the needs were being met in the same table. Percentage of the need met was calculated as follows:

Percentage of the need met $=($ Respondents who received the service they needed $/$ Respondents who needed the service $) * 100$ 


\section{RESULTS}

\section{Patient Characteristics}

The characteristics of the patient population are illustrated in Table 1 . The majority of the patients were Muslim, heterosexual males that had a higher-level education ( $\geq 12$ years). Women constituted $35.4 \%$ of the patients. Most of the patients were either

Table 1. Characteristics of patients receiving HIVIAIDS medical services at the UHCT HIVIAIDS Ambulatory Clinic

\begin{tabular}{|c|c|}
\hline Characteristic & $\begin{array}{c}\text { Population } \\
(n=79)\end{array}$ \\
\hline Age, mean (SD), years & $39.4(11.4)$ \\
\hline Median (range), years & $38(18-79)$ \\
\hline Female, №. $(\%)$ & $28(35.4)$ \\
\hline Heterosexual, №. (\%) & $74(94.7)$ \\
\hline Muslim, №. (\%) & $63(79.7)$ \\
\hline Years abroad, mean (SD), years & $2.7(4.6)$ \\
\hline Median (range), years & $0(0-17)$ \\
\hline Arrested for $\geq 24$ hours, №. (\%) & $18(22.8)$ \\
\hline Ever tried injecting drugs, №. (\%) & $1(1.3)$ \\
\hline Tried injecting drugs in last 12 months, No. (\%) & $1(1.3)$ \\
\hline Years since diagnosis, mean (SD), years & $2.4(3.0)$ \\
\hline Median (range), years & $2(0-16)$ \\
\hline Household member with HIV, №. $(\%)^{1}$ & $20(25.6)$ \\
\hline \multicolumn{2}{|l|}{ Partner situation ${ }^{2}$} \\
\hline Married, living with spouse, №. (\%) & $41(51.9)$ \\
\hline Not married, not living with sexual partner, No. (\%) & $33(41.7)$ \\
\hline \multicolumn{2}{|l|}{ Education } \\
\hline None, No. $(\%)$ & $1(1.3)$ \\
\hline Primary (4 classes), №. (\%) & $5(6.3)$ \\
\hline Secondary (8 classes), №. (\%) & $23(29.1)$ \\
\hline Higher (12 classes), No. (\%) & $39(49.4)$ \\
\hline University, №. (\%) & $11(13.9)$ \\
\hline \multicolumn{2}{|l|}{ Employment } \\
\hline Employed full-time (33-40 hrs/wk), №. (\%) & $20(25.3)$ \\
\hline Employed part-time (less than 33 hrs/wk), №. (\%) & $9(11.4)$ \\
\hline Not working-looking for work, №. (\%) & $22(27.8)$ \\
\hline Not working-not looking for work, №. (\%) & $20(25.3)$ \\
\hline \multicolumn{2}{|l|}{ Mechanism of HIV infection ${ }^{3}$} \\
\hline Heterosexual contact, №. (\%) & $39(47.6)$ \\
\hline Homosexual contact, No. (\%) & $4(4.9)$ \\
\hline Needle sharing, №. (\%) & $2(2.4)$ \\
\hline Blood transfusion, №. (\%) & $8(9.8)$ \\
\hline Don't know, No. (\%) & $14(17.1)$ \\
\hline Other, No. (\%) & $9(11.0)$ \\
\hline
\end{tabular}

${ }^{1}$ Only 78 respondents

${ }^{2}$ Other responses not included in the table

${ }^{3} 82$ responses, respondents selected more than one option married and living with their partner, not married, or living alone. About half of the respondents were unemployed with only $25.3 \%$ of the patients working full-time. Patients had spent a mean of 2.7 years abroad. $22.8 \%$ of the patients had been arrested (generally for not having a visa while abroad). The average duration of HIV infection was 2.4 years and heterosexual contact was the most commonly reported mechanism for acquiring HIV. Around a quarter of the patients lived with someone who was also HIVpositive. There was a low level of reported intravenous drug use.

Comparisons across gender show that there were demographic differences (Table 2). Men were on average 8 years older (42.2 compared to 34.2), had lived abroad for longer periods of time (3.6 years compared to 0.9 years), were more likely to have been arrested (31.3\% compared to $7.1 \%)$, and were less likely to live with a household member with HIV.

\section{Barriers to Care}

The vast majority of patients (97.4\%) said that a major barrier they faced in seeking care was that they did not want others to know that they were HIV-positive. Other barriers that were common amongst the patients were that they did not know where they could find medical help for HIV/AIDS (76.6\%), did not think that they could get help for HIV/AIDS (71.8\%), their medical provider did not know about HIV (70.9\%), they did not think they were eligible for HIV medical help (70.9\%), and/or they did not think that HIV required medical attention (60.1\%) (Table 3 ).

Patients were also asked to list the barrier that was most difficult to overcome when seeking care for HIV/AIDS. The barrier that was most often listed was stigma from the general population (31.4\%) or psychological issues (27.1\%) (Table 4).

\section{Current Medical and Social Needs}

The majority of patients reported needing HIV medical care and help locating a physician or medical provider for ongoing medical attention outside the UHCT HIV/AIDS Ambulatory Clinic. Of the patients that needed HIV medical care, psychological services, or assistance in finding a physician for ongoing care, 97.3, 94.0, and 95.4\% were having their needs met, respectively. In terms of unmet need, almost a quarter of patients in need of education or information on HIV risk prevention were not having their needs met.

Social needs of the patients were high and came in many forms. Most of the social needs of the patients, however, were not being met. Ninety percent of the patients that needed assistance in finding shelter, $95.7 \%$ of the patients that needed assistance in finding food, $92.0 \%$ of the patients that needed assistance with daily activities, $93.7 \%$ of the patients that needed transportation, and $92.1 \%$ of the patients that needed childcare were not having their needs met (Table 5).

\section{DISCUSSION}

Patients seeking care for HIV in Albania face considerable challenges. This study set out to explore characteristics of the patient population, determine barriers that patients experience when seeking care and assesses current medical and social needs 
Table 2. Characteristics of patients receiving HIVIAIDS medical services at the UHCT HIVIAIDS Ambulatory Clinic by gender

\begin{tabular}{|c|c|c|c|}
\hline Characteristic & $\begin{array}{c}\text { Male } \\
(n=51)\end{array}$ & $\begin{array}{l}\text { Female } \\
(\mathrm{n}=28)\end{array}$ & $P$ value \\
\hline Age, mean (SD), years & $42.2(11.5)$ & $34.2(9.2)$ & \multirow{2}{*}{0.006} \\
\hline Median (range), years & $41(23-79)$ & $33(18-51)$ & \\
\hline Heterosexual, No. (\%) & $46(90.2)$ & $28(100.0)$ & 0.15 \\
\hline Married, №. (\%) & $30(58.8)$ & $13(46.4)$ & 0.29 \\
\hline$>$ Secondary (8 classes), №. $(\%)$ & $34(66.7)$ & $16(57.1)$ & 0.40 \\
\hline Muslim, №. (\%) & $40(78.4)$ & $23(82.1)$ & 0.70 \\
\hline Years abroad, mean (SD), years & $3.6(5.1)$ & $0.9(2.9)$ & \multirow{2}{*}{0.003} \\
\hline Median (range), years & $0(0-17)$ & $0(0-15)$ & \\
\hline Employed/student/retired, No. (\%) & $26(51.0)$ & $11(39.3)$ & 0.32 \\
\hline Arrested for $\geq 24$ hours, No. (\%) & $16(31.3)$ & $2(7.1)$ & 0.02 \\
\hline Ever tried drugs, No. $(\%)^{1}$ & $7(14.0)$ & $1(3.6)$ & 0.25 \\
\hline Years since diagnosis, mean (SD), years & $2.4(3.1)$ & $2.6(2.8)$ & \multirow{2}{*}{0.48} \\
\hline Median (range), years & $1(0-16)$ & $2(0-13)$ & \\
\hline Attained HIV through sexual contact, №. (\%) & $24(47.1)$ & $10(35.7)$ & 0.33 \\
\hline Household members with HIV, №. $(\%)^{1}$ & $9(18.0)$ & $11(39.3)$ & 0.04 \\
\hline
\end{tabular}

150 male and 28 female respondents

of HIV-positive patients at the UHCT HIV/AIDS Ambulatory Clinic. In exploring these avenues, we hoped to gain a better perspective of the issues that HIV-positive patients face in Albania and identify possible areas of intervention.

The HIV epidemic in Albania is one that has only recently become more of a priority within the Albanian healthcare sector. This is evidenced with the scale up of care and governmental/nongovernmental prevention programs within Albania (16-19). Still the epidemic may be in its infancy with the majority of patients diagnosed on average 2.4 years prior to this study (Table 1). Of the patients that were eligible to participate in this study, $93 \%$ consented to enroll $(n=79)$; this number represents the majority of patients in Albania that were under HIV/AIDS medical care during this study. Based on the results, the identified epidemic is comprised of mainly heterosexual men in their thirties and forties, yet this is not to say that women are not playing a role in the epidemic. In general men have been abroad for longer periods of time and have been arrested more often (Table 2). Both of these characteristics may increase infection risks within this population, and the $\mathrm{MoH}$ reports that the local epidemic seems to be driven by individuals returning from abroad $(16,17)$. With more women living with household members with HIV, it is also possible that women are more likely to have acquired HIV from domestic partners. Many of the patients were also Muslim, but the percentage of Muslim patients is similar to that in the general population $(79.9 \%)(37)$.

Understanding the current medical and social needs of the patients and the barriers to care they experience will allow further tailoring of interventions towards this population. The patients expressed that barriers to care are abundant and generally related to the social stigma surrounding HIV/AIDS in Albania or the absence of knowledge of both patients and medical providers on HIV/ AIDS. General awareness of where individuals can attain HIV/ AIDS medical care and patient comprehension of eligibility for care were low prior to referral to UHCT HIV/AIDS Ambulatory Clinic (Table 3). Similarly, patients had a number of current medical and social needs (Table 5). The majority of the patients were having their medical needs met, with the exception of HIV education, but were not having their social needs met. This was especially evident in relation to shelter, food, transportation, and childcare. However, it is not possible to distinguish these unmet needs from those of the general population, but patients with HIV may be more burdened by these needs because of their medical conditions.

Previous studies in developing countries have shown that similar barriers to care along with medical and social needs exist and pose an obstacle that must be overcome to achieve necessary coverage of HIV/AIDS medical treatment (26-32). However, what is unique amongst the Albanian population relative to other Central European countries seems to be the generalized widespread unmet social needs. Though current programs in Central and Eastern Europe are being structured to address some of these issues, innovative policy and interventions are necessary to help reduce barriers to HIV/AIDS care in the Albanian healthcare system (38).

These barriers to care and current medical and social needs offer a variety of ways in which the Albanian health and social sectors can intervene to facilitate patient attainment of HIV medical care. Developing mechanisms to reduce the social stigma around HIV/AIDS, educating the public on the availability of HIV/AIDS medical care in Albania along with prevention measures for HIV/AIDS, and increasing education for medical providers on HIV/AIDS may allow for increased coverage of patients needing medical attention for HIV/AIDS within Albania. If the local epidemic continues to rise, it will be vital to minimize the barriers that patients face when seeking care, so that proper diagnosis and intervention can be pursued. Addressing the current medical and social needs of patients under care at the UHCT HIV/AIDS Ambulatory Clinic may also minimize the number of patients 
Table 3. Barriers to care experienced by patients receiving HIVIAIDS medical care at UHCT HIVIAIDS Ambulatory Clinic

\begin{tabular}{|c|c|}
\hline Barrier & $\begin{array}{c}\text { Population } \\
(n=79)\end{array}$ \\
\hline Did not want people to know I had HIVIAIDS ${ }^{1}$ & $76(97.4)$ \\
\hline Did not know where I could find medical help for HIVIAIDS ${ }^{1}$ & $59(76.6)$ \\
\hline Did not know that I could get help for HIV/AIDS² & $56(71.8)$ \\
\hline My doctor or nurse did not know about HIVIAIDS & $56(70.9)$ \\
\hline I was not eligible for HIVIAIDS medical help & $56(70.9)$ \\
\hline Did not think that HIVIAIDS required medical help ${ }^{1}$ & $47(61.0)$ \\
\hline I was afraid that I was going to lose my job and/or house because of HIVIAIDS ${ }^{2}$ & $43(55.1)$ \\
\hline Too sick to get medical help & $40(50.6)$ \\
\hline The services cost too much money & $34(43.0)$ \\
\hline No transport available & $27(34.2)$ \\
\hline Mental problems (like depression, anxiety, dementia, etc.) kept me from getting medical help for HIVIAIDS & $19(24.1)$ \\
\hline There are too many instructions that I have to follow ${ }^{1}$ & $18(23.4)$ \\
\hline People at the hospital or clinic made me feel worse about myself for having HIVIAIDS & $16(20.3)$ \\
\hline No childcare available & $14(17.7)$ \\
\hline People at the hospital or clinic treated me unfairly because of my HIVIAIDS & $11(13.9)$ \\
\hline I had to wait too long to see a doctor for HIVIAIDS & $9(11.4)$ \\
\hline There was too much paperwork ${ }^{1}$ & $6(7.8)$ \\
\hline I was afraid to get in trouble with the law and/or police & $2(2.5)$ \\
\hline
\end{tabular}

177 respondents

278 respondents

Table 4. Most difficult barrier to care experienced by patients receiving HIVIAIDS medical care at UHCT HIVIAIDS Ambulatory Clinic

\begin{tabular}{|c|c|}
\hline Barrier & $\begin{array}{c}\text { Population } \\
\left(n=70^{1}\right)\end{array}$ \\
\hline Stigma from the general population (not wanting others to know of infection), №. (\%) & $22(31.4)$ \\
\hline Stigma from family members ${ }^{2}$, No. $(\%)$ & $4(18.2)$ \\
\hline Stigma from medical staff ${ }^{3}$, No. (\%) & $3(13.6)$ \\
\hline Psychological problems, №. (\%) & $19(27.1)$ \\
\hline Self-guiltt, No. (\%) & $8(42.1)$ \\
\hline Too sick, No. (\%) & $9(11.4)$ \\
\hline No information available on HIVIAIDS or where to get treatment, №. (\%) & $5(7.1)$ \\
\hline Afraid of family members having HIVIAIDS, №. (\%) & $4(5.7)$ \\
\hline No childcare available, №. (\%) & $3(4.3)$ \\
\hline Financial problems, №. $(\%)$ & $2(2.9)$ \\
\hline Did not believe physician, №. (\%) & $1(1.4)$ \\
\hline No transport available, №. (\%) & $1(1.4)$ \\
\hline Fear of losing job, №. (\%) & $1(1.4)$ \\
\hline Was on alternative therapy, №. (\%) & $1(1.4)$ \\
\hline
\end{tabular}

${ }^{1}$ Some patients responded with more than one barrier that was the most difficult to overcome.

${ }^{2}$ Stigma from family members is a subset of the stigma category. The percentage is calculated from the 22 respondents of the stigma barrier.

${ }^{3}$ Stigma from the medical staff is a subset of the stigma category. The percentage is calculated from the 22 respondents of the stigma barrier.

${ }^{4}$ Self-guilt is a subset of psychological problems category. The percentage is calculated from the 19 respondents of the psychological problems barrier.

who are lost to follow-up. Previous experiences in Albania have shown that patients lost to follow-up can be high - from $1 / 1 / 2008-8 / 1 / 2009$, there were 23 patients that missed taking
ART for an average of 10.4 months (Morrison S and Harxhi A, unpublished results). Therefore, alleviating patient needs may be instrumental in retaining patients. 
Table 5. Needs of patients receiving HIVIAIDS medical services at UHCT HIVIAIDS Ambulatory Clinic

\begin{tabular}{|c|c|}
\hline Patient need in last 12 months & $\begin{array}{c}\text { Population } \\
(n=79)\end{array}$ \\
\hline HIV medical services, №. (\%) & $77(97.5)$ \\
\hline Received HIV medical services, №. $(\%)^{1}$ & $72(97.3)$ \\
\hline Psychologist or psychiatric services, №. $(\%)^{2}$ & $51(65.4)$ \\
\hline Received psychologist or psychiatric services, No. $(\%)^{3}$ & $47(94.0)$ \\
\hline Assistance in finding a doctor for ongoing medical services, №. (\%) & $69(87.3)$ \\
\hline Received assistance in finding a doctor for ongoing medical services, No. $(\%)^{4}$ & $62(95.4)$ \\
\hline Assistance in finding a shelter or housing, №. (\%) & $41(51.9)$ \\
\hline Received assistance in finding a shelter or housing, №. $(\%)^{5}$ & $4(10.0)$ \\
\hline Assistance with finding meals or food, No. (\%) & $48(60.8)$ \\
\hline Received assistance with finding meals or food, №. $(\%)^{6}$ & $2(4.3)$ \\
\hline Assistance with completing daily activities or chores, No. (\%) & $50(63.3)$ \\
\hline Received assistance with completing daily activities or chores, №. $(\%)^{3}$ & $4(8.0)$ \\
\hline Transportation assistance, №. $(\%)^{2}$ & $51(65.4)$ \\
\hline Received transportation assistance, №. $(\%)^{7}$ & $3(6.3)$ \\
\hline Childcare assistance, №. (\%) & $43(54.4)$ \\
\hline Received childcare assistance, №. $(\%)^{8}$ & $3(7.9)$ \\
\hline Education or information on HIV risk prevention, No. (\%) & $44(55.7)$ \\
\hline Received Education or information on HIV risk prevention, No. $(\%)^{9}$ & $31(75.6)$ \\
\hline
\end{tabular}

${ }^{1} 74$ respondents, ${ }^{2} 78$ respondents, ${ }^{3} 50$ respondents, ${ }^{4} 65$ respondents, ${ }^{5} 40$ respondents, ${ }^{6} 47$ respondents, ${ }^{7} 48$ respondents, ${ }^{8} 38$ respondents, ${ }^{9} 41$ respondents

The most important limitation of this study is that these patients are exceptional in the fact that they have navigated themselves through the barriers of the healthcare sector in Albania. Their responses may therefore not necessarily be generalised to the entire Albanian HIV-positive population, yet the study offers an initial insight into problems facing this community. However, it is likely that those who have not yet made it to care would face even more obstacles since they have not yet been able to access the appropriate medical care infrastructure. Using respondentdriven approaches like that used in the Albanian Behavioural and Biological Surveillance Survey may provide better access to those at-risk for HIV/AIDS and inform the healthcare sector on barriers to care not revealed in this study (18). Other limitations of this study are rooted in self-report bias and the small sample size. In general, patient self-report tends to bias results for studies related to medical care $(26,36,39)$. However, self-report remains an effective way to glean information on barriers within the health care system especially in the developing world (26). With only 79 patients enrolled in this study, small sample size may prevent generalization of the study results. The local HIV epidemic in Albania is still relatively small and the number of patients under HIV medical care in Albania was less than one hundred at the time of this study. Therefore, this study effectively assesses the majority of the then current HIV-positive patient population in Albania.

Minimizing these barriers to care, as well as current medical and social needs, may enable individuals who are HIV-infected or unsure of their status to receive a proper care. Since Eastern Europe has currently the fastest growing rate of HIV in the world, proper surveillance, diagnosis, and treatment is paramount, as interventions at these levels may be instrumental to halting a possible epidemic in nearby Central European nations such as Albania. With the proper structuring of future interventions within the Albanian population, including the increased availability of knowledge about HIV and treatment options along with decreasing social stigma and providing more education to medical providers about HIV, it may be possible to provide for better quality of life and longevity in the HIV infected population.

\section{Acknowledgements}

This work was funded by a Stanford University EMEG Medical Scholars Grant to Shane D. Morrison. The authors have no conflicts of interest. The authors thank Dritan Agalliu of Stanford University School of Medicine for translation of the instrument into Albanian; Cynthia Castro of the Stanford Prevention Center for feedback on the development of the project; Pranvera Kulla of the UHCT HIV/AIDS Ambulatory Clinic for help with consenting and recruiting patients for the study; and the staff at the UHCT Infectious Diseases Clinic and the Stanford University School of Medicine Department of Pediatric Infectious Diseases for making this project possible.

\section{REFERENCES}

1. Joint United Nations Programme on HIV/AIDS (UNAIDS); World Health Organization. AIDS epidemic update: December 2007. Geneva: UNAIDS; 2007.

2. Joint United Nations Programme on HIV/AIDS (UNAIDS). Global report: fact sheet on HIV/AIDS for Eastern Europe and Central Asia. Geneva: UNAIDS; 2007.

3. World Health Organization. Epidemiological fact sheets on HIV and AIDS, 2008 update. Geneva: WHO; 2008. 
4. United Nations Programme on HIV/AIDS; World Health Organization. Fact sheet on global HIV/AIDS. Geneva: UNAIDS; 2009.

5. Joint United Nations Programme on HIV/AIDS. United nations AIDS epidemic update. Geneva: UNAIDS; 1999.

6. World Health Organization. World Health Statistics 2008. Geneva: WHO; 2008.

7. Cohen J. Late for the epidemic: HIV/AIDS in Eastern Europe. Science. $2010 \mathrm{Jul}$ 9;329(5988):160, 162-4.

8. Cohen MS, Hellmann N, Levy JA, DeCock K, Lange J. The spread, treatment, and prevention of HIV-1: evolution of a global pandemic. J Clin Invest. 2008 Apr;118(4):1244-54.

9. Jasny B, Mueller K, Roberts L. HIV/AIDS: Eastern Europe. Introduction. Science. 2010 Jul 9;329(5988):159.

10. Kilmarx PH. Global epidemiology of HIV. Curr Opin HIV AIDS. 2009 Jul; $4(4): 240-6$.

11. Institute de Veille Sanitaire. HIV/AIDS surveillance in Europe, mid-year report, 2003. Saint-Maurice, France: Institute de Veille Sanitaire; 2003.

12. Hamers FF, Downs AM. HIV in central and eastern Europe. Lancet. 2003 Mar 22;361(9362):1035-44.

13. Perno CF, Cozzi-Lepri A, Balotta C, Bertoli A, Violin M, Monno L; I.CO.N.A Study Group. Low prevalence of primary mutations associated with drug resistance in antiviral-naive patients at therapy initiation. AIDS. 2002 Mar 8;16(4):619-24.

14. United Nations Albania. Access to HIV information and treatment, care and support for people living with HIV is a human right. Tirana: United Nations Albania; 2009.

15. The World Bank. Albania: key indicators. New York: The World Bank; 2008.

16. Ministry of Health, Republic of Albania. Albania country progress report. Tirana: Ministry of Health, Republic of Albania; 2007.

17. Ministry of Health, Republic of Albania. Let's keep Albania a low HIV prevalence country: the national strategy of prevention and control of HIV/AIDS in Albania 2004-2010. Tirana: Ministry of Health, Republic of Albania; 2003.

18. Survey Working Group. Albania - behavioral and biological surveillance study report. Tirana: Institute of Public Health; 2006.

19. Harxhi A, Pernaska L. Rapid assessment and response on HIV/AIDS among especailly vulnerable young people in Albania: a country report. Tirana; 2002 .

20. United Nations Children's Fund. Rapid assessment and response - Tirana. Tirana: UNICEF; 2004

21. Ministry of the Interior of the Republic of Slovenia; International Organization for Migration. The Republic of Albania migration profile. Ljubljana: Ministry of the Interior of the Republic of Slovenia; 2007.

22. Ciccozzi M, Gori C, Boros S, Ruiz-Alvarez MJ, Harxhi A, Dervishi M, et al. Molecular diversity of HIV in Albania. J Infect Dis. 2005 Aug 1;192(3):475-9.

23. Salemi M, de Oliveira T, Ciccozzi M, Rezza G, Goodenow MM. Highresolution molecular epidemiology and evolutionary history of HIV-1 subtypes in Albania. PLoS One. 2008 Jan 2;3(1):e1390.

24. Boulle A, Ford N. Scaling up antiretroviral therapy in developing countries: what are the benefits and challenges? Sex Transm Infect. 2007 Dec;83(7):503-5.

25. Kaida A, Gray G, Bastos FI, Andia I, Maier M, McIntyre J, et al. The relationship between HAART use and sexual activity among HIV-positive women of reproductive age in Brazil, South Africa, and Uganda. AIDS Care. 2008 Jan;20(1):21-5.
26. Posse M, Meheus F, van Asten H, van der Ven A, Baltussen R. Barriers to access to antiretroviral treatment in developing countries: a review. Trop Med Int Health. 2008 Jul;13(7):904-13.

27. Cook PA, Downing J, Wheater CP, Bellis MA, Tocque K, Syed Q, et al. Influence of socio-demographic factors on distances travelled to access HIV services: enhanced surveillance of HIV patients in north west England. BMC Public Health. 2009 Mar 6;9:78.

28. Delva W, Wuillaume F, Vansteelandt S, Claeys P, Verstraelen H, Broeck DV, et al. HIV testing and sexually transmitted infection care among sexually active youth in the Balkans. AIDS Patient Care STDS. 2008 Oct;22(10):817-21.

29. Fakoya I, Reynolds R, Caswell G, Shiripinda I. Barriers to HIV testing for migrant black Africans in Western Europe. HIV Med. 2008 Jul;9 Suppl 2:23-5.

30. Gruskin S, Tarantola D. Universal Access to HIV prevention, treatment and care: assessing the inclusion of human rights in international and national strategic plans. AIDS. 2008 Aug;22 Suppl 2:S123-32.

31. Otieno PA, Kohler PK, Bosire RK, Brown ER, Macharia SW, John-Stewart GC. Determinants of failure to access care in mothers referred to HIV treatment programs in Nairobi, Kenya. AIDS Care. 2010 Jun;22(6):72936.

32. Tuller DM, Bangsberg DR, Senkungu J, Ware NC, Emenyonu N, Weiser SD. Transportation costs impede sustained adherence and access to HAART in a clinic population in southwestern Uganda: a qualitative study. AIDS Behav. 2010 Aug;14(4):778-84.

33. Bobrova N, Sarang A, Stuikyte R, Lezhentsev K. Obstacles in provision of anti-retroviral treatment to drug users in Central and Eastern Europe and Central Asia: a regional overview. Int J Drug Policy. 2007 Aug; 18(4):3138.

34. Kelly JA, Somlai AM, Benotsch EG, Amirkhanian YA, Fernandez MI, Stevenson LY, et al. Programmes, resources, and needs of HIV-prevention nongovernmental organizations (NGOs) in Africa, Central/Eastern Europe and Central Asia, Latin America and the Caribbean. AIDS Care. 2006 Jan; 18(1):12-21.

35. Lee BW, Sathyan P, John RK, Singh K, Robin AL. Predictors of and barriers associated with poor follow-up in patients with glaucoma in South India. Arch Ophthalmol. 2008 Oct;126(10):1448-54.

36. 36. Simoni JM, Kurth AE, Pearson CR, Pantalone DW, Merrill JO, Frick PA. Self-report measures of antiretroviral therapy adherence: a review with recommendations for HIV research and clinical management. AIDS Behav. 2006 May;10(3):227-45.

37. Pew Research Center. Mapping the global muslim population: a report on the size and distribution of the world's muslim population. Washington: Pew Research Center; 2009.

38. Lazarus JV, Laukamm-Josten U, Atun RA, Liljestrand J, Vase I, Matic S Encouraging innovation: ten research priorities for achieving universal access to HIV/AIDS prevention, treatment and care in Europe by 2010. Cent Eur J Public Health. 2008 Sep;16(3):95-8.

39. Wang H, He G, Li X, Yang A, Chen X, Fennie KP, et al. Self-Reported adherence to antiretroviral treatment among HIV-infected people in Central China. AIDS Patient Care STDS. 2008 Jan;22(1):71-80.

Received October 4, 2010

Accepted in revised form March 8, 2011 